\title{
Molecular microbial ecology of lignocellulose mobilisation as a carbon source in mine drainage wastewater treatment
}

\author{
Anna M Clarke ${ }^{1 *}$, Ralph Kirby ${ }^{2}$ and Peter D Rose ${ }^{1}$ \\ ${ }^{1}$ Environmental Biotechnology Research Unit (EBRU), Rhodes University, Grahamstown, South Africa \\ ${ }^{2}$ Department of Life Sciences, National Yang-Ming University, Taipei, Taiwan
}

\begin{abstract}
The community structure of complex microbial consortia which develop in lignocellulose packed passive treatment systems for acid mine drainage remediation were investigated. An understanding of interactions between these populations is important in determining mechanisms by which such systems operate. A degrading packed bed reactor was packed with lignocellulositic material as a sole carbon source and fed continuously with simulated acid mine drainage. Samples were collected every two months at different depths of the reactor to isolate the total genomic DNA and PCR amplify section of 16S rDNA gene. PCR primers, GM5F and 907R incorporating GC clamp were used to amplify 586-bp region of 16S rDNA gene. Denaturing gradient gel electrophoresis (DGGE) indicated clearly a highly differentiated pattern of r-DNA - derived amplificates between different depths of the bioreactor. Predominant DGGE bands were further excised, reamplified, cloned and sequenced. Sequencing analysis revealed phylogenetic affiliation of specific bacterial populations in different depths of the bioreactor.
\end{abstract}

\section{Introduction}

Previous studies undertaken by Rhodes University and Pulles, Howard and de Lange Inc. (PHD) in the use of lignocellulose packed reactor in passive treatment of acid mine drainage (AMD) had shown that certain factors play an important role in their sustained operation over the long time.

Little is known, however, why under certain conditions the performance of these reactors may decline after a period of several months.

This study was part of an Innovation Fund Project in which these problems were addressed and the performance of the microbial consortia shown to play an important role in sustaining operational performance.

The novel degrading packed bed reactor was developed based on these insights and the IMPI passive treatment process has been successfully implemented by PHD.

The carbon source provided for microbiota in this study was lignocellulositic material in the form of pine chips and grass as these are easily available in the country and thus make the process economically vialable. Lignocelluloses are some of the most abundant biological polymers on earth. However due to the complexicity of its components and chemical structure of lignin in particular its enzymatic degradation is known to be very difficult (Bumpus, 1989; Burland and Edward, 1999; Crawford and Crawford, 1976; Crawford, 1981; Crawford et al., 1983). Except for a few lignin solubilising actinomycetes (Crawford and Crawford, 1976; Crawford, 1981; Crawford et al., 1983), lignin degradation by microorganisms is known to be mainly the domain of aerobic fungi (Achi, 1994; Blondeau, 1989; Bumpus, 1989; Dehorter and Blondeau, 1992). Little is known about and the degradation of lignin in biosulphidogenic environment (Parek et al., 2001) however, several studies suggest that the contribution of anaerobic

This paper was originally presented at the 2004 Water Institute of South Africa (WISA) Biennial Conference, Cape Town, South Africa, 2-6 May 2004.

* To whom all correspondence should be addressed.

푱+2746 6222656; fax: +2746 6222656;; e-mail: ebru@ru.ac.za organisms to degradation of lignin has been underestimated and should be reevaluated (Kim et al., 1997). Recent findings point to anaerobic degradation of aromatic compounds (Burland and Edward, 1999; Meckenstock et al., 2000) We suspected that strong involvement of microorganisms belonging to different physiological groups and their collaboration may govern the degradation process and the aim of this project was to look for distinct population patterns.

\section{Materials and methods}

\section{Sample collection}

Samples were collected from a DPBR. Specimens for DNA extraction were collected directly into a sterile $50 \mathrm{~m} \ell$ Falcon tubes (Laboratory \& Scientific Equipment Co.) and kept on ice or at $4^{\circ} \mathrm{C}$ until processed (usually within 4 days).

\section{DNA extraction and purification}

Prior to extraction samples were pelleted by centrifugation, washed once with $2 \mathrm{x}$ buffer A (200 mM Tris [pH 8.0], 50 mM EDTA, 200 $\mathrm{mM} \mathrm{NaCl}, 2 \mathrm{mM}$ sodium citrate, $10 \mathrm{mM} \mathrm{CaCl} 2$ ) and one part $50 \%$ glycerol (Bond, P.L. Appl.Env.2000), and then resuspended in 0.5 $\mathrm{m} \ell$ of $2 \mathrm{x}$ buffer $\mathrm{A}$ in $2 \mathrm{~m} \ell$ microcentrifuge tube. It was necessary to include this washing step as low $\mathrm{pH}$ of the specimen may cause the hydrolysis of DNA, and high concentration of metals could contaminate the extracted DNA and further have inhibitory effect on subsequent PCR. Polyadenilic acid ( $200 \mu \mathrm{g} / \mathrm{m} \ell)$, and lysozyme ( $3 \mathrm{mg} / \mathrm{m} \ell$ ) were added to the suspension and incubated for 40 minutes at $37^{\circ} \mathrm{C}$. Samples were subjected to four cycles of freezing in liquid nitrogen and heating for one minute at $80^{\circ} \mathrm{C}$. Proteinase K (2 mg/m $\ell$ ) and SDS (10\% wt/vol) were added to the mixture, and this was incubated overnight at $37^{\circ} \mathrm{C}$. Cell lysates were extracted with phenol-chloroform-isoamyl alcohol (24:24:1). Nucleic acids were precipitated with 2.5 volumes of $96 \%$ rectified ethanol overnight at $-20^{\circ} \mathrm{C}$, pelleted by centrifugation and resuspended in TE buffer (10 mM Tris, 1 mM EDTA, pH 8.0). 
Community 16S rRNA genes were amplified by PCR in $25 \mu \ell$ reaction containing approximately $30 \mathrm{ng}$ of purified DNA per $\mathrm{m} \ell$, $1 \mathrm{x}$ PCR buffer, $200 \mu \mathrm{M}$ concentration of each of the four deoxynucleoside triphosphates, 2.5 mM MgCl2, $0.04 \mathrm{U}$ of High Fidelity PCR System Taq (Roche Biochemicals), $350 \mathrm{mM}$ reverse and forward primers per microliter. Both primers GM5 F (5' - cct acg gga ggc agc ag - 3') and 907 R (5' - cgc ccg ccg cgc ccc gcg ccc gtc ccg ccg ccc ccg ccc gcc gtc aat tcc ttt gag ttt - 3') incorporating GC clamp were obtained from IDT USA. Amplification was performed on Hybaind PCR Sprint thermocycler using touchdown PCR procedure with initial denaturtion at $95^{\circ} \mathrm{C}$ followed by 28 cycles of denaturation at $94^{\circ} \mathrm{C}$ for $30 \mathrm{~s}$, annealing at $68^{\circ} \mathrm{C}$ decreasing every 4 cycles by $2^{\circ} \mathrm{C}$ for $45 \mathrm{~s}$, extension at $72^{\circ} \mathrm{C}$ and completed with final extension at $72^{\circ} \mathrm{C}$ for 5 minutes. PCR product was purified using QIAquick PCR purification columns (Qiagen). These were quantified on a $0.8 \%$ agarose gel.

\section{Denaturing gradient gel electrophoresis (DGGE)}

DGGE was done according to previously described protocol (Muyzer, 1993). The PCR products were separated on denaturing gradient from 40\%(6\% [wt/vol] acrylamide-bisacrylamide [37.5:1], $8 \%$ formamide, $1.4 \mathrm{M}$ urea, $2 \%$ glycerol) to $50 \%$ (6\% [wt/vol] acrylamide-bisacrylamide [35.5:1], 20\% formamide, 3.5 M urea, $2 \%$ glycerol). The electrophoresis was performed in an electrophoresis cell (Sigma-Aldrich) with 1 x TAE buffer (Tris-acetateEDTA) at $60^{\circ} \mathrm{C}$ and $150 \mathrm{~V}$ for 4.5 hours. DNA was stained with CyberGreen and visualised as described before (Muyzer, 1993). Bands were excised with sterilised scalpel blade transferred to $200 \mu \ell$ Tris-EDTA buffer. The DNA was extracted, reamplified and cloned.

\section{Cloning}

DNA extracted from DGGE bands was reamplified with GM5 F and $907 \mathrm{R}$ primers. The motilities of the resulting product were checked by DGGE as described before in order to ensure the pure product. Cloning was performed by using pGemT-easy vector (Promega USA) in accordance with the manufacturer instruction. The cells were transformed into JM 109 High Efficiency Component Cells (Promega, USA). Restriction digest using EcoR1 was performed in order to confirm the insert. Plasmids were extracted using QIA miniprep from Qiagen.

\section{Sequencing}

Plasmids were sequenced using BigDye Terminator 3 sequencing kit (Applied Biosystems) with 100 to 200 ng of template DNA according to the manufacturer instruction. For initial analysis, partial sequence was obtained using primer GM5 F. Extended sequences were obtained by using universal sequencing primers $\mathrm{T} 7$ and SP6 (Promega USA). The extension products were purified using DNA Clean \& Concentrator columns (Zymo Research, USA). DNA sequence was determined on an automated ABI 3100 Prism Genetic Analyzer at Rhodes University, Grahamstown, South Africa.

\section{Phylogenetic analysis}

Clones from the various DGGE bands spread over sample position and time were sequenced. The $16 \mathrm{~S}$ sequences obtained from these

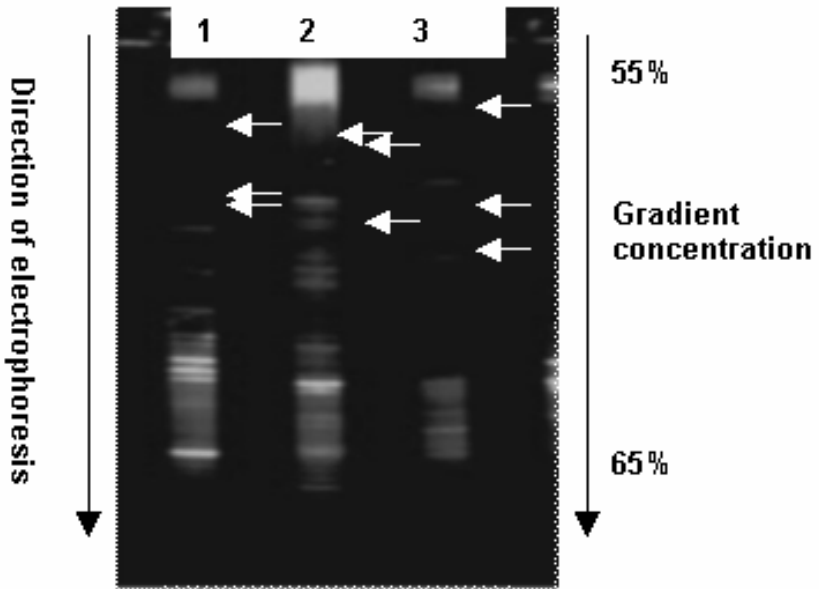

Figure 1

Comparison of bacterial community in Degrading Packed Bed Reactor (DPBR). Each lane represents Cyber Green stained DGGE pattern of PCR product. Lane 1: Bottom of the reactor; lane 2: middle; lane 3: top of the reactor.

clones in one direction were aligned using Clustal $\mathrm{X}$ and classified into groupings based on their sequence similarity. Representative sample clones were sequenced in both directions. The latter sequences were aligned with each other and a range of other $16 \mathrm{~S}$ sequences from the GenBank database including those most closely related to each sequence on Blast analysis. The aligned sequences were analyzed phylogenetically using Neighbor Joining algorithm from Clustal X using two Archeaebacterial 16S rRNA sequences as the outgroup

\section{Results and discussion}

\section{DGGE Analysis}

To analyse the microbial population for the presence of specific bacteria, the DGGE separation patterns were stained with cyber green and excised for the elution of DNA. The eluted DNA was sequenced.

The DGGE revealed different pattern in distances in migration indicating different species present within single amplificate. This was confirmed by sequencing analysis, results of which are presented in Table 2. However, the number of fragments, which could be visualised on DGGE gel, may in some cases, underestimate the actual diversity of a microbial population and should be considered as a lower limit of an estimation of the total number of bacterial species present.

\section{Phylogenetic analysis}

Figure 2 shows a N-J analysis of the $16 \mathrm{~S}$ rRNA sequences.

It is clear that one group of bacteria predominate in the first third of the column for the whole of the bioremediation process. These organisms are Gram +ve low $\mathrm{G}+\mathrm{C}$ eubacteria related to the Clostridia according to the phylogenetic analysis. Although part of the main Clostridium branch containing as closest species Clostridium thiosulfatireducans, a proteolytic, thiosulfate and sulfur-reducing bacterium and Clostridium peptidovorans, and a peptide fermenting organism from an anaerobic digestor, they group with a range of as yet uncultivated species obtained from environmental samples. The latter include AJ488074, part of a consortium in- 


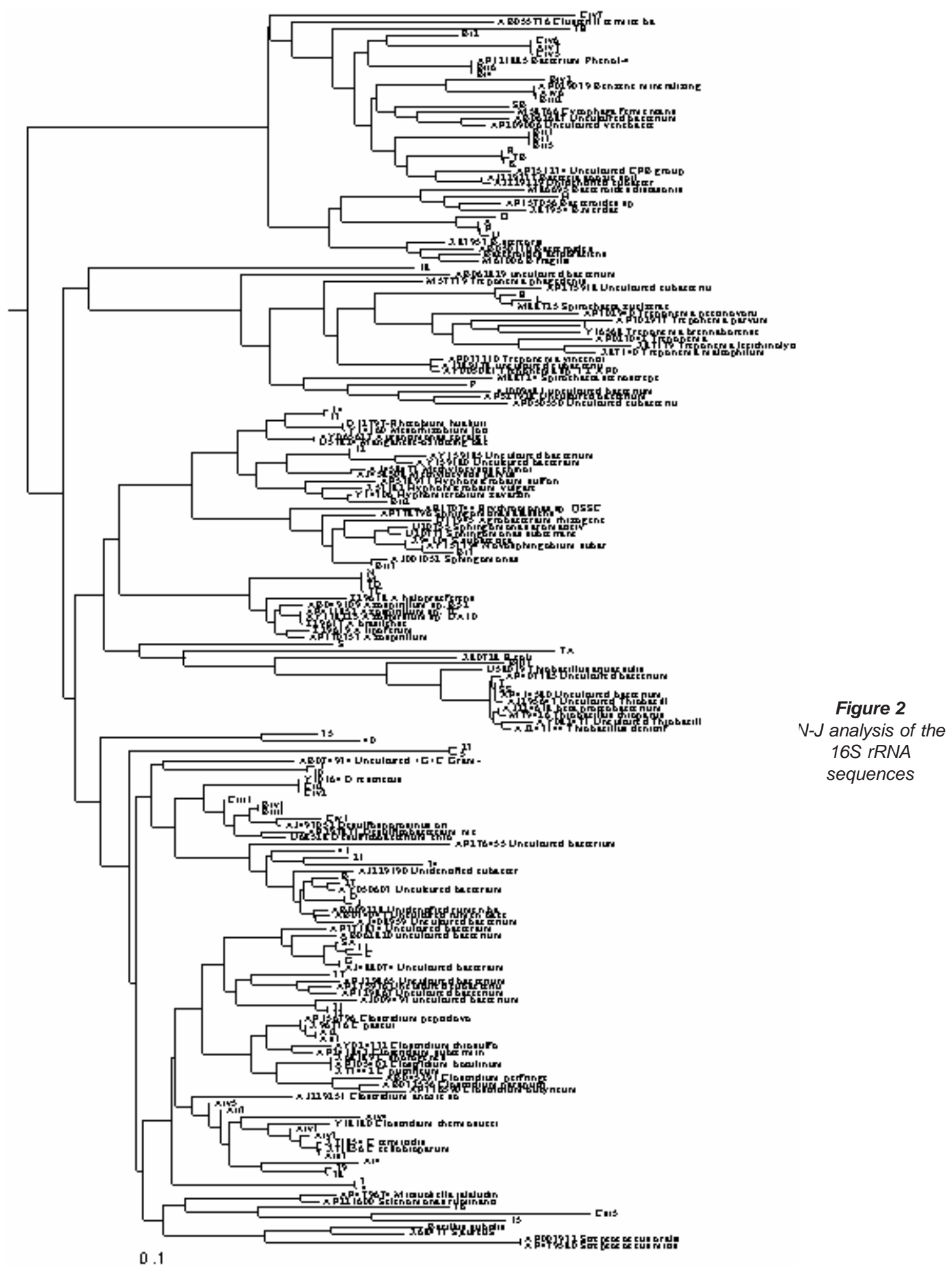

volved in dechlorination of chlorobenzene, AB062820, a termite gut bacterium, AF371834, a pig gut bacterium, AJ229251, a polysaccharide degrading bacterium from anoxic soil and AF129865/Ay275916, both from lignocellulose anaerobic digestors. Initially, also present in the first third of the column are a variety of Spirochaetales most closely related to Trepomema spp. The closest, AF275918, is an uncultivated eubacteria from an anaerobic digestor; while Treponema vincentii and uncultivated eubacteria AY995981 are oral strains. Finally, AJ289178 is an strain from an anaerobic corneal ulcer. However, these Treponema strains are not detected at later stages in the bioremediation process.
In the second third of the column, one group of related organism is present throughout the bioremediation process. These are strains closely related to Bacteriodes and Cytophaga. However, this group is quite diverse and although it groups together on a signal branch of the phylogenetic analysis in Fig. 1, it can be subdivided into two subgroups. One subgroup, containing A, F and $\mathrm{H}$, groups with Bacteroides has AF157056 from murine gut biota as closest. The major group containing Bacteroides fragilis, Bacteroides uniformis and Bacteroides sterconis all form part of the same Bacteroides branch as A, F and $\mathrm{H}$. In contrast, $\mathrm{K}$ is most closely related to Cytophaga fermentens as well as two uncultivated 
eubacteria, AB062687, a member of an ethylbenzene degrading, sulphate reducing consortium and AF209006, isolated from a shallow submarine hydrothermal vent. Also close are AF120885, an organism from part of a phenol degrading consortium and AF029039, part of a sulphate reducing, benzene mineralising consortium.

During the first half of the bioremediation, strains related to Azospirillum are also present in the middle of the column and are most similar to three Azospirilium brasilense spp., including one nitrogen fixer from fuel contaminated Artic soil, AF411852. These Azospirillum spp. seem to decline during the second half and the fermentation and are replaced by Thiobacillus spp., These species branch within Thiobacillus aquaesulis and Thiobacillus denitrificans, but closest to Thiobacillus thioparus, a thiosulphate oxidising bacteria, AF414580 from a uranium reducing community and AJ224608 from a thiosulphate oxidising community. Also appearing during this period in this part of the column are Group 5 strains related to Gram +ve rumen bacteria.

In the final third of the column, rumen bacteria mentioned above are present throughout the rest of the bioremediation process. Group 3 bacteria then appear followed by Group 2 and Group 6 bacteria in the presence of the Group 5 bacteria. The Group 5 rumen bacteria are related to a number of sulphate reducing bacteria such as Desulfosporosinus and Desulfilobacterium but are closest to a range of uncultivated bacteria involved in both dechlorination and digestion in the rumen and colon.

\section{Conclusions}

It appears that the mobilisation of the complex carbon source in the sequential pattern observed here must be sustained in order to maintain the operational performance of the DPBR. It has been shown that the initial fermentative groups play the important role in poising the redox of the system. The supplementation of this group has been developed in the IMPI process with long-term application of the process showing promising results.

The results of the sequencing analysis, demonstrate clear pattern of hierarchy within microbial community, with simple organisms present at the top of the reactor and gradually developing more specialised species of phenol degraders followed by cellulose degrading organisms.

Molecular biology methods used in this study clearly illustrate rich diversity of the microorganisms in the degrading packed bed reactor. Distribution of the microbiota in the DPBR is a convincing indication of distinct nutritional niches that microorganisms establish in the environment in order to proceed with biodegradation. Clear competition and synthrophy between the community structure leads to the sequence of events that dictates chain of chemical reactions resulting in degradation of lignocelluloses material within bioreactor.

\section{Acknowledgements}

We wish to thank all members of PHD (Pullis, Howard and De Lange) for the use of their lab facilities, for setting up the bioreactors and providing assistance with managing and maintenance of the reactors.

This project was funded by Innovation Fund (DACTS).

\section{References}

ACHI OK (1994) Growth and coal-solubilizing activity of Penicillium simplicissimum on coal related aromatic compounds. Biores. Technol. 48 (1) 53-57.

BLONDEAU R (1989) Biodegradation of natural and synthetic humic acids by white-rot fungus Phanerochaet chrysosporium. Appl. Environ. Microbiol. 22 1282-1285.

BUMPUS JA (1989) Biodegradation of polycyclic aromatic hydrocarbons by Phanerochaete chrysosporium. Appl. Environ. Microbiol. 55 (1) 154-158.

BURLAND SM and EDWARD E (1999) Anaerobic benzene biodegradation linked to nitrate reduction. Appl. Environ. Microbiol. 65 5529533.

CRAWFORD DL and CRAWFORD RL (1976) Microbial degradation of lignocellulose: The lignin component. Appl. Environ. Microbiol. 31 714-717.

CRAWFORD RL (1981) Lignin Biodegradation and Transformation. Wiley-Interscience, New York.

CRAWFORD DL et al. (1983) Lignin degradation by Streptomyces viridosporus: Isolation and characterization of a new polymeric lignin degradation Intermidiate. Appl. Environ. Microbiol. 45 895-904.

DEHORTER R and BLONDEAU R (1992) Extracellular enzyme activieties during humic acid degradation by the white rot fungi Phanerochaete chrysosporium and Trametes versicolor. FEMS Microbiol. Lett. 109 117-123.

KIM SK et al. (1997) Biodegradation of recalcitrant organic matter under sulphate reducing and methanogenic conditions in the landfill column reactors. Water Sci. Res. 36 91-98

MECKENSTOCK RU et al. (2000) Anaerobic naphthalene degradation by a sulphate reducing enrichment culture. Appl. Environ. Microbiol. 133 249-256.

MANZ W et al. (1992) Phylogenetic oligodeoxynucleotide probes for the major subclasses of Proteobacteria: Problems and solutions. System. Appl. Microbiol. 15 593-600.

MUYZER W et al. (1993) Profiling of complex microbial population by denatuturing gradient gel electrophoresis analysis of polymerase chain reaction-amplified genes coding for $16 \mathrm{~S}$ rRNA. Appl. Environ. Microbiol. 59 695-700.

PAREK S et al. (2001) Degradation of lignin and lignin model compounds under sulphate reducing conditions. Water Sci. Technol. 44 351-358. 